\title{
Study on CSF Chloride Level-A Predictor of Mortality in TBM
}

\author{
Dr. Antony Kisku ${ }^{1}$,Dr. Kiran Kumar M.N. ${ }^{2}$,Dr. \\ M.R.Akhouri ${ }^{3}$ \\ Associate Proffesor ${ }^{3}$,Post Graduate ${ }^{1,2}$ Rajendra Institute Of Medical Sciences,Ranchi,Jharkhand
}

\begin{abstract}
Tubercular meningitis(TBM) is very common problem in paediatrics age group.It occurs when tubercle bacilli invades the membrane or the fluid surrounding the brain and spinal cord.Till now there is no such geniuine predictor has been found to predict the mortality in TBM.The CSF chloride in these patients have been done to see its any association with mortality in TBM.
\end{abstract}

Keywords: TBM,CSF,Chloride.

\section{Introduction}

Tubercular meningitis is a serious complication of childhood tuberculosis, commonly occurring in the age group of 6 months to 4 years of age(1).

It occurs when tuberculosis bacteria(Mycobacterium Tuberculosis) invades the membranes and fluid surrounding the brain and spinal cord(2).

As per stastical data till now the mortality rate being too high $(38 \%)\{3\}$.

A lot of confusion arises in differentiating various form of meningitis on the basis of CSF The following study has been done to see whether CSF chloride level helps in differenating various forms of meningitis and also in predicting mortality in TBM. Previously too a lots of studies has been done to use CSF chloride level as a marker for classifying this various forms of meningitis(4), but no study has been done till now to use any CSF marker for predicting mortality in TBM picture

\section{Aims And Objectives}

To study CSF chloride level in various forms of meningitis(TB,viral,Pyogenic)

To do a comparative study of CSF chloride level in TBM cases who died and survived

To see whether CSF chloride has any relationship with mortality in TBM cases

\section{Material And Methods}

Around 70 patients, who got admitted in RIMS paediatrics department with clinical features of Meningitis and diagnosed to be TBM on the basis of CSF study and history were studied. Among the control group other diagnosed cases of viral meningitis(20cases) and bacterial meningitis(20cases)were also included. The CSF chloride level among various forms of meningitis were studied. Lastly the CSF chloride level of various patients of TBM who ultimately survived or died werecompared

\section{Inclusion Criteria}

All the patients of paediatrics age group with signs and symptoms of meningitis were included in the study(4).

\section{Methodology}

The CSF of above patients were obtained and was sent for routine cytological and biochemical studies with special emphasis to csf chloride level.All the cases of TBM were observed till their death or discharge from the hospital.

\section{Results}

The following results were obtained on the basis of respective study

No. Of cases Of Viral And Pyoge nic Meningitis With Their Mean Csf Chlorid e Level
\begin{tabular}{llll} 
CSFCHLORIDE LEVEL(Meq/L) & $115-127$ & $100-114$ \\
\hline CASESOFPYOGENIC MENINGITIS & 14 & 6 \\
CASESOFVIRALMENINGITIS & 18 & 2
\end{tabular}

The maximum no of cases of Pyogenic meningitis(14/20) had normal values of CSF chloride Only 6 cases had slightly lower level of csf chloride level. Even the maximum cases of viral meningitis(18/20)had

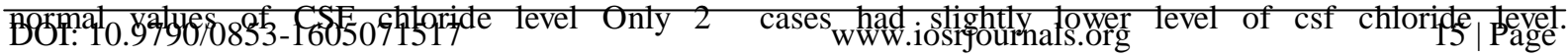




\section{No.Of Deaths In Tbm With Their Respective Csf Chloride Level}

\begin{tabular}{|l|l|l|l|l|}
\hline & & & & \\
\hline & & & & \\
\hline No.Ofdeaths & 3 & 6 & 8 & 13 \\
\hline
\end{tabular}

The maximum number of cases of TBM who died(13)had their Mean CSF chloride level below 60NO. OF

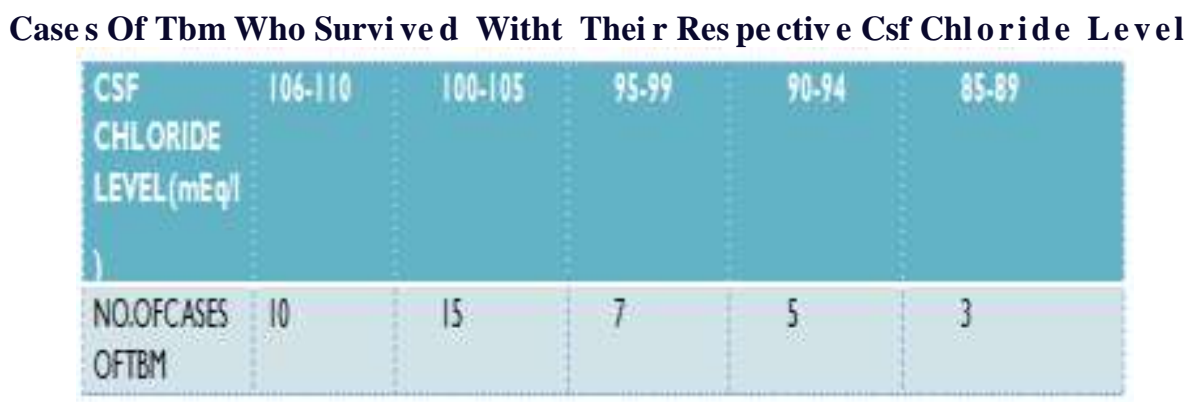

The maximum no. of cases of TBM who survived(15) had their mean CSF chloride level in the range of 100 105 .

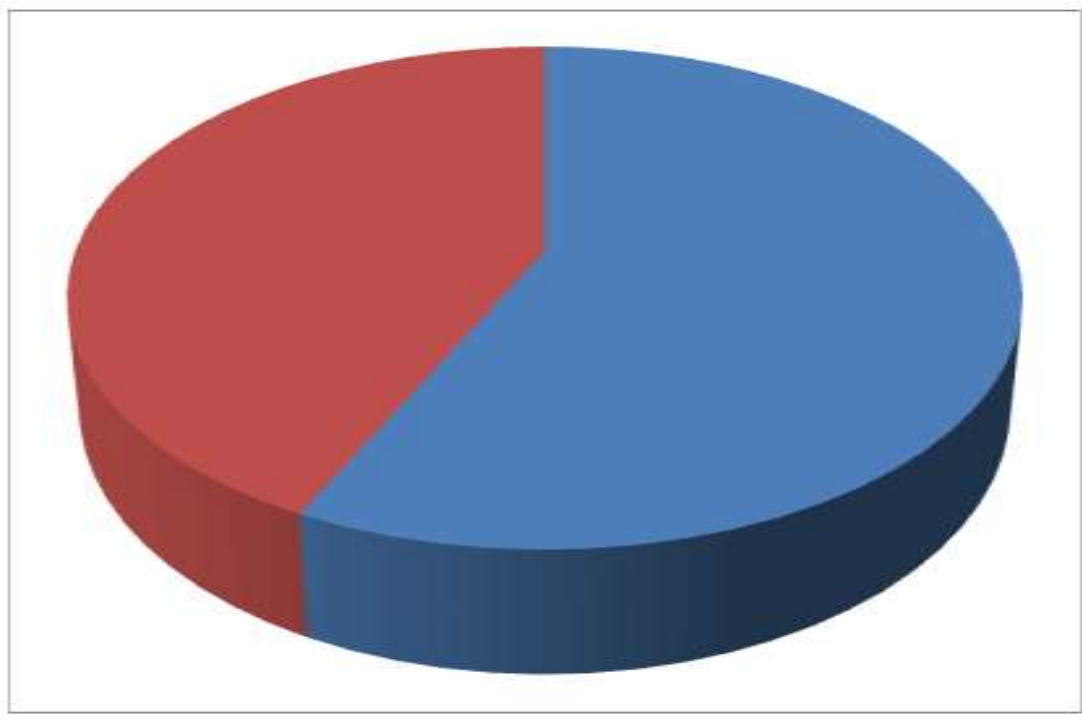

LIVE-40,DEATHS-30

A total of 110 children presenting with meningitis were included in this study. The mean value of CSF chloride level in pyogenic meningitis were $112.8 \mathrm{meq} / \mathrm{L}$. The mean value of CSF chloride level in viral meningitis were $110.5 \mathrm{meq} / \mathrm{L}$. The mean value of CSF chloride level in TBM cases who died ere $79.25 \mathrm{meq} / \mathrm{L}$ where as those who survived had their mean CSF chloride level were $96.98 \mathrm{meq} / \mathrm{L}$ As per the chi square test done(the expected CSF chloride level being taken from G.J.Owens study and the observed value taken from the present study), the $P$ value obtained of the study obtained was $0.04\left(p=0.04, x^{2}=26.8, n f=2\right)$. The $p$ value obtained on CSF chloride level, normal or decreased in all 3 forms of meningitis came out to be $0.001\left(\mathrm{p}=0.001, \mathrm{x}^{2}=80.9, \mathrm{nf}=2\right)$. The $\mathrm{p}$ value obtained on csf chloride level in TBM showing variation with survival and death came out to be $0.001\left(\mathrm{p}=0.001, \mathrm{x}^{2}=18.5, \mathrm{nf}=1\right)$.

\section{Discussion}

As per the study done it could be quite clearly seen that out of 70 cases of TBM being studied 30 cases died, so we can very easily understand the graveness of TBM. India being an endemic nation to TB and TBM being very common in paediatric age group it is the need of the hour of to have some index to predict mortality in such cases. Grierson et al in their study(1980) showed that $19 \%$ of the pyogenic meningitis case had CSF chloride level in the range of $115-120 \mathrm{mEq} / \mathrm{l}$ while $60 \%$ of TBM cases had CSF chloride level below $100 \mathrm{mEq} / 1$. 


\section{Limitations}

Number of cases being small.

Most of the patients of TBM who died mostly had associated complications like severe respiratory distress,DIC etc.

\section{Conclusion}

The mean CSF chloride level was normal or slightly decreased in cases of viral or pyogenic meningitis. The normal value of CSF chloride being taken as (116-127 mEq/l ).

$>$ The CSF chloride was decreased in almost every cases of TBM.

$>$ The following study can turn out to be a great help in differentiating various forms of meningitis and also in predicting mortality in TBM.

$>$ Now as per the limitations being mentioned earlier a lot of further studies are required before standardizing above study as an authentic marker in meningitis

[1]. Tuberculosis in children-kab ra- $4^{\text {th }}$ edition

\section{Bibliography}

[2]. Nelson textbook of paediatrics $-20^{\text {th }}$ edition

[3]. Paediatrics Neurology-Veena karla- $2^{\text {nd }}$ edition

[4]. G.J. Owens study on csf. 